\title{
Soil bacterial community and functions directly respond to grazing exclusion in a Leymus chinensis steppe of Inner Mongolia, China
}

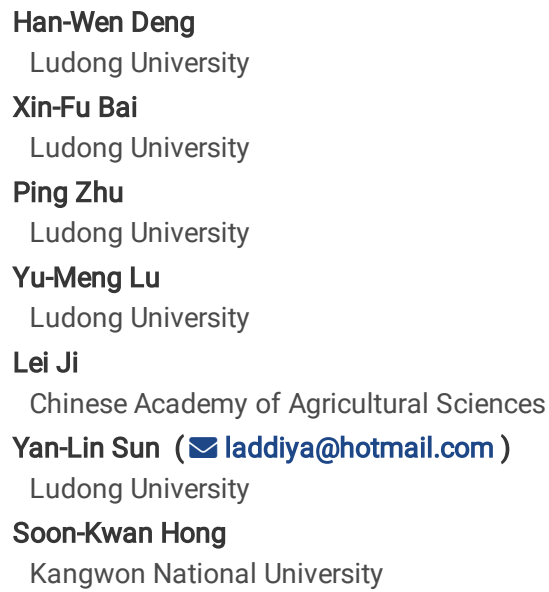




\section{Abstract \\ Background}

Grazing exclusion is a common grassland management strategy for restoring degraded grasslands. Its effectiveness on optimizing plant species community, increasing vegetation diversity and biomass, improving soil fertility, has been widely documented in literatures. However, little is known on the responses of the absolute abundance and the ecological functions of soil bacterial community to long-term grazing exclusion.

\section{Result}

In this study, the absolute abundance, diversity, and ecological functions of soil bacterial community were determined by the high-throughput absolute quantitative sequencing technology on a long-term grazing exclusion (40 years, GE) area and three free grazing areas (FGs) within a Leymus chinensis steppe of Inner Mongolia, China, and analyzed the driving forces leading to the variations in soil bacterial community and functions. Our results showed that there was significantly higher soil bacterial abundance in the GE than the FGs along with corresponding variations in vegetation and soil properties. With the decrease of vegetation aboveground biomass, the absolute abundance of soil bacterial community also decreased. Among the phyla of the soil bacterial communities, the relative abundances of Chloroflexi and Firmicutes phyla were especially lower, and that of Verrucomicrobia phylum was higher in the GE than the FGs; the absolute abundances of Euryarchaeota and Microgenomates phyla were especially higher in the GE than the FGs.

\section{Conclusions}

This study suggested that long-term grazing exclusion significantly increased the absolute abundance, changed soil bacterial composition, and especially enhanced bacterial motility and chemotaxis. In particular, soil organic matter was the important agent to influence and connect vegetation and soil. This work will enrich our understanding of the responses of absolute abundance, diversity, and function of the soil bacterial community to long-term grazing exclusion, and help the evaluation of grassland degradation degree and restoration strategy effectiveness.

\section{Background}

Soil microbes play key roles in ecosystems and mediate many ecological processes, such as nutrient cycling [1], litter decomposition [2], and ecological restoration [3]. Beyond our previous understanding that plant species can gather specific microbes and influence root-associated microbes [2, 4], additional studies show that soil microbes can also regulate plant species composition, and influence plant diversity $[5,6]$. Thus, the study of the quantitative linkages between the soil microbial community and its corresponding environmental parameters is necessary and important for us to further understand some ecological processes and variations in ecological functions [6].

Grasslands occupy approximately $20 \%$ of the terrestrial surface and play an important role in providing multiple ecosystem and cultural services, and supporting peoples' livelihoods [7, 8]. The Leymus chinensis steppe is typical steppe, occupying approximately $25 \%$ of all grasslands in Inner Mongolia, China [9]. In recent decades, because of climate deterioration, overgrazing, and unreasonable human activities, severe deterioration phenomenon have been increasingly occurring in this steppe [10-12]. Grazing exclusion, as one of the most common and effective strategies for restoring degraded grasslands [8, 13, 14] has been widely believed to increase the vegetation productivity to a more productive state [12-13]. In addition, grazing exclusion has been considered to improve the soil bacterial diversity in semiarid grasslands [15, 16], and enhance the growth of arbuscular mycorrhizal fungi [17]. However, the detailed responses of the absolute abundance, diversity, and function of the soil microbial community to long-term grazing exclusion are still not clear.

To further understand this question, we selected a Leymus chinensis steppe of Xilin Gol grassland, Inner Mongolia, China, which exhibits an important geographical location and landscape elements in the world, and examined the absolute abundance and diversity of soil microbial community, and their corresponding vegetation and edaphic indicators, to predict their ecological functions in one 40 years grazing exclusion area and three free grazing areas using a high-throughput absolute quantitative sequencing technique. Based on the previous understanding of the positive effects of grazing exclusion on vegetation biomass and diversity in this steppe, we hypothesized that long-term grazing exclusion would also have a large effect on the abundance, diversity, and ecological functions of soil microbial communities, which would connect and influence vegetation and edaphic indicators in turn. Our results showed that long-term grazing exclusion significantly increased the absolute abundance of soil bacterial communities, and enhanced bacterial chemotaxis and motility. Soil organic matter was considered as the most important driving factor of soil properties linking vegetation and soil microbial community. This work would help to further understand the multifaceted effects of long-term grazing exclusion on soil bacterial community, and contribute to theories concerning the regulation of biodiversity in general. Uncovering the underlying mechanisms driving bacterial community variation in soil will help us to predict the potential effects on soil bacterial communities based on the corresponding information of vegetation and soil properties, and thus understand the role of soil bacterial communities in various ecosystem processes.

\section{Results}

\section{Vegetation and soil information of study sites}

One grazing exclusion area (GE), and three free grazing areas (FGs) having different vegetation biomass per unit area and representative vegetation composition, were selected in this study. Based on the evaluation criteria of grassland degradation [18] and the vegetation diversity and biomass of four study sites (Table 1), GE was considered as the non-degraded area, and FG1, FG2, and FG3 were initially identified as the slightly degraded area, moderately 
degraded area, and severely degraded area, respectively. To verify the determination of degradation degree of each area, the correlations between degradation degree and diverse factors about vegetation biomass and diversity were analyzed (Table 1). The results suggested that total plant species richness (SR) and aboveground biomass (AB), Shannon-Wiener diversity index $(\mathrm{H})$, Pielou evenness index (E), litter mass (LM), and the species richness of different functional types (effective species, gramineous species, forb species, and shrub species), and the aboveground biomass of different functional types (effective species, gramineous species, and annual and biennial species) were all significantly related with the determination of degradation degree, further proving the rationality of degradation degree evaluation of the study sites. Because the sampling sites were set in the same steppe, the soil properties and enzyme activities should not be too different, while due to the different grassland management of grazing exclusion and free grazing, there were indeed certain impacts on soil nutrients, especially on nitrogen and phosphorus contents (Table 2). Referring to the relationship between soil and degradation degree, only soil organic matter content (SOM) had significantly negative response (Table 2).

\section{Effect of grazing exclusion on soil bacterial abundance}

Long-term grazing exclusion resulted in the obvious increase of absolute abundance of soil bacterial community based on the high-throughput $16 \mathrm{~S}$ rRNA absolute quantitative sequencing result (Fig. 1). Acidobacteria, and Actinobacteria, and Proteobacteria were the predominant phyla in all soil samples, which accounting for at least $12.8 \%$ of the bacterial community. Except for these three phyla, the proportions of Bacteroidetes, Planctomycetes, and Chloroflexi were relatively high in most soil samples, accounting for more than $5 \%$ of the bacterial community. Gemmatimonadetes, Thaumarchaeota, candidate division WPS1 , Verrucomicrobia, Nitrospirae, Firmicutes, Armatimonadetes, and Cyanobacteria were present in relatively low proportions, accounting for more than $1 \%$. Ignavibacteriae, Latescibacteria, Candidatus Saccharibacteria, Euryarchaeota, and Elusimicrobia showed lower proportions, with relative abundances of more than $0.1 \%$.

Based on the Kruskal-Wallis test, a total of 3 and 5 phyla exhibited significant differences $(P<0.05)$ in absolute and relative abundance of soil bacterial community, respectively, among different study sites (Figs. 2, 3). Among them, two phyla, Euryarchaeota and Cyanobacteria/Chloroplast both showed significant differences in the absolute and relative quantitative analysis of soil bacterial community among the four study sites. Euryachaeota,

Microgenomates, and Verrucomicrobia exhibited high abundance in GE, and low abundance in FGs; Chloroflexi and Firmicutes exhibited relatively low abundance in GE, but high abundance in FGs; Cyanobacteria/Chloroplast exhibited very low abundance in GE and severely degraded area (FG3), relatively higher abundance in FG1 and FG2.

\section{Effect of grazing exclusion on soil bacterial composition}

As shown in the Venn map, most of the soil bacterial species in different study sites (accounting for 63.10\%-64.98\%) were overlapping (Fig. 4). However, considering the different important orders within and between groups, the partial least squares discriminant analysis (PLS-DA) results showed that four study sites could be completely separated from each other, although the FG2 and FG3 were relatively close (Fig. 5). This indicated that grazing exclusion could not only increase the absolute abundance of soil bacterial community, but also influence the composition of soil bacterial community.

\section{Effect of grazing exclusion on the ecological functions of bacterial community}

Using PICRUSt software, the COG functional annotations and KEGG pathways were used to predict the ecological functions of bacterial community. A total of $24 \mathrm{COG}$ categories were annotated for the functions; those with relatively high abundance were related to transcription, amino acid transport and metabolism, signal transduction mechanisms, cell wall/membrane/envelope biogenesis, energy production and conversion, carbohydrate transport and metabolism, replication, and recombination and repair, etc. The two-way analysis of variance (ANOVA) results showed that 5 functional annotations were significantly different $(P<0.05)$ among the four study sites, including general functions predicted only, carbohydrate transport and metabolism, signal transduction mechanisms, replication, recombination and repair, and cell motility (Additional file 1). Among these functions, general functions predicted only, and carbohydrate transport and metabolism were more active in FG3 than in GE, while the other three functional annotations with significant differences were the opposite and, being more active in GE than in FG3.

Based on the PICRUSt results, a total of 312 KEGG pathways were involved in this study. The ANOVA results showed that 63 KEGG pathways were significantly different $(P<0.05)$ among the four study sites (Additional files 2,3 ). Among them, 3 KEGG pathways with significant differences overlapped with the COG categories with significant differences among the four study sites, which were general functions predicted only, replication, recombination and repair, and cell motility.

According to the comprehensive analysis of the predicted bacterial function, it indicated that long-term grazing exclusion could effectively improve cell motility by increasing the contents of bacterial motility proteins and improving flagellar assembly, thus significantly enhancing bacterial chemotaxis (Additional file 3 ). In addition, the biosynthesis of isoflavonoids which participated in plant growth, development and stress resistance [19, 20], was significantly higher in GE than in the other three free-grazing grasslands (Additional file 2), thus, it was not difficult to recognize that GE possessed higher glycan biosynthesis and metabolism, and higher activity of glycosyltransferases than FG (Additional file 3). This was because the isoflavonoid biosynthesis required the participation and catalysis of a large number of glycan and glycosyltransferases [21]. This result suggested that long-term grazing exclusion could significantly enhance isoflavonoid biosynthesis by increasing glycan biosynthesis and metabolism and glycosyltransferase activities and thus favor plant growth, development and stress resistance.

\section{Correlations between bacterial community and environmental factors}

To understand the effects of environmental factors on soil bacterial community, we examined multiple indices related to vegetation diversity, biomass, soil properties, and enzyme activities, and estimate their correlations with the bacterial community. The Pearson correlation results indicated that no matter the relative abundance or absolute abundance of the bacterial community, these environmental factors all showed significant correlations with them $(P<0.05$, 
Table 3). According to the redundancy analysis (RDA) between soil bacterial community and vegetation biomass indexes, the soil bacterial community showed the closest correlations with shrub species aboveground biomass (SAB, Fig. 6a), SR, H, (Fig. 6B), and SOM (Fig. 6c).

Due to the accurate discrimination of grassland degradation degree for four investigated study sites based on vegetation biomass and diversity (Table 1), we introduced the grassland degradation degree (DG) as an important factor, and used it to further analyze the correlation of the soil bacterial phylum with environmental factors. As for vegetation biomass, annual and biennial species aboveground biomass (AAB) and DG were divided into one category, the other factors were grouped as one category (Fig. 6a). Compared with the vegetation diversity factors, DG formed one category by itself, and the annual and biennial species diversity (ASR) was had the worst consistency with other factors (Fig. 6b). As for soil properties, the soil pH value (PH) and soil bulk density (SBD) were grouped with DG, and the other factors were grouped together (Fig. $6 \mathrm{c}$ ). As for soil enzyme activities, DG was separated from any one of three soil enzyme activities (Fig. 6d).

Through the correlation analysis with diverse environmental factors and soil bacterial community in the phylum level, we found vegetation biomass and vegetation diversity showed similar results of that all bacteria were divided into three big groups showing different responses to various factors: one group which were positively related to most vegetation biomass and diversity factors, but negatively related to DG and AAB, included Euryarchaeota,

Microgenomates, candidate division WPS-1, Verrucomicrobia, Proteobacteria, Acidobacteria, Ignavibacteriae, Omnitrophica, Elusimicrobia, and Parcubacteria; one group which were negatively related to most factors, but positively related to DG and AAB, included Thaumarchaeota and Firmicutes; the other group had no significant relations with most factors, such as BRC1, Armatimonadetes, Latescibacteria, Bacterioidetes, Hydrogenedentes, Actinobacteria, Nitrospirae, and Pacearchaeota, and so on. Compared with the correlations with soil properties and soil bacterial community in the phylum level, microorganisms could also be divided into three categories according to their response patterns: one group which were positively related to most soil property factors except for PH, SBD, and DG, included Bacteroidetes, Hydrogenedentes, Armatimonadetes, BRC1, candidate division WPS-1, and Omnitrophica; one group which were negatively related to most soil property factors, included Pacearchaeota, Thaumarchaota, and Firmicutes; the other group did not show significant relations with most factors, or only showed significant relations with very few factors, such as Parcubacteria, Ignavibacteriae, Elusimicrobia, Euryarchaeota, Microgenomates,

Verrucomicrobia, Acidobacteria, Proteobacteria, and so on. Based on the correlation analysis between soil enzyme activities and soil bacterial community in the phylum level, the phyla which responded significantly to them were greatly reduced. All microorganisms could be divided into four categories: one group were positively related to the soil enzyme activities, including Omnitrophica, candidate division WPS-1, Armatimonadetes, Bacteroidetes, Hydrogenedentes, and BRC1; one group were negatively related to them, including Thaumarchaeota, Firmicutes, Latescibacteria, Actinobacteria, and Nitrospirae; one group were only negatively related to DG and urease activity, including Euryarchaeota, and Microgenomates; the other group had no significant relations with the soil enzyme activities, such as Parcubacteria, Ignavibacteriae, Elusimicrobia, Proteobacteria, Verrucomicrobia, Acidobacteria, and so on.

It was worth nothing that Bacteroidetes, Hydrogenedentes, Armatinomadetes, and BRC1 and Pacearchaeota did not respond to vegetation factors, but they had remarkable responses to soil properties and enzyme activities. However, the bacterial phyla, such as Euryarchaeota, Microgenomates, Verrucomicrobia, Acidobacteria, Proteobacteria, Parcubacteria, Ignavibacteriae, and Elusimicrobia, which had significantly positive responses to vegetation factors, had no or few responses to soil properties and enzyme activities. To be noted, Latescibacteria, Actinobacteria, and Nitrospirae did not significantly respond to vegetation factors and most soil properties, but significant-negatively to available potassium content (AK), and soil enzyme activities.

\section{Discussion}

\section{Increases in the soil bacterial abundance following grazing exclusion}

Grazing exclusion as a practical restoration and management regime [22], has been widely considered to significantly affect vegetation, and soil microbial community $[16,23]$. Since the existence of soil microbes ultimately depends on autotrophs for their supply of nutrients, the plant biomass, diversity and community composition are always considered to be closely related to both the biomass and diversity of soil microbial communities [2]. Some studies have confirmed that grazing exclusion could significantly affect the activity, functional diversity, and structure of the soil microbial community [5, 24-26], while some studies have shown that grazing exclusion could reduce soil microbial diversity, or have no significant impact on soil microbial community [5, 27, 28]. Combined with our understanding that vegetation could affect microbial community, the effect of grazing exclusion on soil microbial community was actually caused by the variations in vegetation biomass and diversity induced by grazing exclusion. The main reason for the inconsistency on the effects of grazing exclusion on soil microbial community was that there were also different opinions on the effects on vegetation diversity, which would directly affect soil microbial community, especially on its diversity. In this study, the vegetation biomass and diversity, and SOM contents were found to be significantly increased by grazing exclusion (Tables 1,2), so was the absolute abundance of soil bacterial community (Fig. 1). Although the diversity of soil bacterial community could not be directly affected by grazing exclusion, the soil bacterial absolute abundance which could be directly affected by grazing exclusion, was positively correlated with bacterial diversity $(r=0.613, P<0.05)$.

\section{Soil organic matter as the most important intermediary between vegetation and soil}

Soil organic matter has been considered as the important factor to connect vegetation and soil microbial community [29-31]. On one hand, the residues of plants and soil bacteria will shift to one part of soil organic matter; on the other hand, soil bacteria could promote to decompose litter and plant residues, thus increasing soil organic matter content. In the present study, grazing exclusion significantly increased SOM, which was the unique factor among soil property factors that had significant correlation with degradation degree (Table 2). This was closely related to grazing exclusion-induced increase in the aboveground biomass and soil bacterial abundance. Predictably, SOM was positively correlated with the aboveground biomass of shrub ( $\mathrm{r}=0.907, P<0.01)$, and annual and biennial species $(r=0.682, P<0.05)$, and the richness of gramineous $(r=0.588, P<0.05)$, forb $(r=0.867, P<0.01)$, and annual and biennial species $(r=0.874$, $P<0.01)$ in this study. This suggested that the contribution to increased SOM was not limited to fine forage, but also annual and biennial species and even shrubs. As the important factor of soil fertility, SOM was positively correlated with SBD $(r=-0.908, P<0.01)$, soil water content (SWC, $r=0.874, P<0.01)$, total 
nitrogen content (TN, $\mathrm{r}=0.889, P<0.01)$, alkali-hydrolyzable nitrogen content (AHN, $\mathrm{r}=0.885, P<0.01)$, total phosphorus content (TP, $\mathrm{r}=0.888, P<0.01)$, available phosphorus content (AP, $\mathrm{r}=0.668, P<0.05)$, phosphatase activity $(\mathrm{r}=0.723, P<0.01)$, and sucrase activity $(\mathrm{r}=0.729, P<0.01)$. This suggested that increased SOM meant soil softness, water content, $\mathrm{N}$ and $\mathrm{P}$ pools and enzyme activities increased. SOM was also significantly correlated with soil bacterial abundance $(\mathrm{r}=0.611, P<0.05)$, but not with soil bacterial diversity $(\mathrm{r}=0.48, P=0.114)$. This result was consistent with Hooper et al. [31] that grazing exclusion resulted in the increase in soil bacterial abundance with a concomitant increase in diversity. Therefore, due to the removal of grazing pressure, grazing exclusion effectively improved biomass and diversity of vegetation, which also increased SOM and soil bacterial abundance. These could lead to the enhancement of soil fertility, which in turn could promote vegetation growth.

\section{Variations in ecosystem functions induced by grazing exclusion}

The enhancement of bacterial chemotaxis indicated that soil bacteria had a higher ability to seek benefits and avoid harm, so that they could better adapt to the dynamic environment [32], which was also the key for adjusting the structure and composition of the soil microbial community and allowing the successful colonization of a certain soil environment [33]. Therefore, grazing exclusion enhanced the bacterial chemotaxis and motility, and in fact improved some other important ecosystem properties, such as decomposition, nutrient flow rates, and resistance and resilience to disturbances.

\section{Conclusions}

Grazing exclusion could significantly increase the biomass and diversity of vegetation, and soil bacterial abundance, and enhance soil fertility and biological activities. In particularly, the soil organic matter was the key intermediary to undertake the corresponding variations of vegetation and soil and connect them. The improvement in bacterial motility and cell chemotaxis were the most significant variations in the function of the bacterial community following grazing exclusion, which would further improve the potential and ability of soil bacterial community to resist environmental stresses.

\section{Methods}

\section{Study areas}

This study was conducted at the Leymus chinensis steppe ( $43^{\circ} 33-34^{\prime} \mathrm{N}, 116^{\circ} 40-41^{\prime} \mathrm{E}, 1210-1241 \mathrm{~m}$ above sea level) within Xilin Gol grassland of Inner Mongolia, China. This steppe is located in the wide hilly valley formed on the basis of the second basalt, belonging to the temperate and semi-arid continental climate [34]. The annual mean temperature is $-0.4^{\circ} \mathrm{C}$, the annual mean precipitation is $300-400 \mathrm{~mm}$ with $70 \%$ falling during the growing season from June to August [35]. The soil of this steppe is chestnut calcareous soil [34]. The dominant plant species in this steppe are originally Stipa grandis, Leymus chinensis, Achnatherum sibiricum and Agropyron cristatum. However, due to overgrazing, some areas in this steppe have seriously degraded, and then the dominant plant species of degraded areas have gradually changed to Artemisia frigida [35]. For preserving and recovering plant diversity and productivity, this seriously degraded areas have been fenced to be excluded from grazing and any human activities since 1979 [36]. Grazing intensity restriction strategy has been implemented outside the fenced steppe by the government. In this study, one grazing exclusion area (GE), and three free grazing areas (FGs) were selected to investigate the effect of grazing exclusion on soil bacterial community. Considering the possible interference of spatial heterogeneity, we delineated three big enough sampling site $\left(600 \times 400 \mathrm{~m}^{2}\right)$ in each study area, and randomly selected three plots $\left(100 \times 100 \mathrm{~m}^{2}\right)$ in each site. Three quadrats $\left(1 \times 1 \mathrm{~m}^{2}\right)$ were randomly selected in each plot. Our experimental area, regardless of precipitation, temperature or other environmental factors, e.g. soil type and nutrient status, were basically the same, which could effectively avoid confounding factors affecting the results.

\section{Soil sampling}

Sampling took place in GE, and FGs in June 2019. The sampling day was selected on a sunny day. Before soil sampling, there had been no rain for more than one week. Soil was sampled by drilling a $7 \mathrm{~cm}$ diameter soil core into 0-10 cm, 10-20 cm, and 20-30 cm soil layer in each quadrat, respectively. Each soil sample was divided into two sets. One set was preserved in $-80^{\circ} \mathrm{C}$ liquid nitrogen for DNA extract. The other set was air-dried, and ground to measure the belowground biomass, enzyme activities, physical and chemical properties of soil samples.

\section{DNA extraction and PCR amplification}

The genomic DNA of each soil sample was extracted using the FastDNA ${ }^{\mathrm{TM}}$ SPIN Kit for Soil DNA Extraction (MP Biomedicals, LLC, OH, USA) according to the manufacturer's instructions. The DNA quality was evaluated by detection with agarose gel electrophoresis (MultiDoc-lt Digital imaging system, UVP, Cambridge, UK), concentration assay (NanoDrop2000, Thermo Fisher Scientifi, USA), and $\mathrm{OD}_{260} / \mathrm{OD}_{280}$ ratio (NanoDrop2000, Thermo Fisher Scientifi, USA). The DNAs with satisfactory concentrations and good quality were used for subsequent high-throughput 16S rRNA PCR amplification (Genesky Biotechnologies Inc., Shanghai 201315, China).

\section{Measurements}

The aboveground biomass $\left(\mathrm{AB}, \mathrm{g} \mathrm{m}^{-2}\right.$ ) of different types of species was reported by the weight of aboveground parts of corresponding species in each quadrat. The species richness (SR) of different types of species was reported by the number of corresponding species in each quadrat. The vegetation belowground biomass $\left(\mathrm{BB}, \mathrm{g} \mathrm{m}^{-3}\right)$ was calculated by the weight of total vegetation roots in each layer soil taken by a cylindrical soil block with a diameter of 7 $\mathrm{cm}$. The soil bulk density (SBD) was calculated by dividing the weight of a cylindrical soil block with a diameter of $5 \mathrm{~cm}$ and $5 \mathrm{~cm}$ in height by its volume. And then, the cylindrical soil block (fresh weight, FW) was oven dried weighted at $105^{\circ} \mathrm{C}$ for $24 \mathrm{~h}$, and weighted again to get the dry weight (DW). The soil water content (SWC) was calculated as (FW-DW) $100 \% / F W$. The pH value of the soil (PH) was determined with the potentiometry method. Seven soil nutrient parameters were measured in this study: total nitrogen, alkali-hydrolyzable nitrogen, total phosphorus, available phosphorus, total potassium, available 
potassium, and organic matter. The total nitrogen content (TN) was determined using the Kjeldahl nitrogen determination method (NY/T53-1987); the alkalihydrolyzable nitrogen content (AHN) was determined using the alkaline hydrolysis diffusion method; the total phosphorus content (TP) was determined using the alkali fusion-Mo-Sb colorimetric method (NY/T88-1988); available phosphorus content (AP) was determined using the sodium bicarbonate leaching-MoSb colorimetric method (LY/T1233-1999); the total potassium content (TK) was determined using $\mathrm{HF}_{-} \mathrm{HClO}_{4}$ heating digestion method [37]; the available potassium content (AK) was determined using ammonium acetate extraction method [38]; and the soil organic matter content (SOM) was determined with $\mathrm{K}_{2} \mathrm{Cr}_{2} \mathrm{O}_{7}$ oxidation volumetric method [39].

\section{Data analysis}

The Shannon-Wiener diversity $(\mathrm{H})$ and the Pielou evenness $(\mathrm{E})$ of vegetation species were calculated according to the methods of West [40]. The two-way analysis of variance (ANOVA) based on Duncan's multiple-range test in SPSS 20.0 for Windows (SPSS Inc., Chicago, IL, USA) was used to examine differences among different study sites, and correlations between soil bacterial community and environmental factors. The high throughput absolute and relative quantitative sequencing results have been uploaded and published in Sequence Read Archive (SRA) data of NCBI servers (https://www.ncbi.nlm.nih.gov/sra), with the accession number of PRJNA646998.

\section{Abbreviations}

GE: grazing exclusion area; FGs:free grazing areas; BB:belowground biomass; SBD:soil bulk density; FW:fresh weight; DW:dry weight SWC:soil water content $\mathrm{PH}$ :soil pH value; TN:total nitrogen content:AHN:alkali-hydrolyzable nitrogen content; TP:total phosphorus content; AP:available phosphorus content; TK:total potassium content; AK:available potassium content; SOM:soil organic matter content; SR:total plant species richness; ESR:effective species richness; GSR:gramineous species richness; ASR:annual and biennial species richness; FSR:forb species richness; SSR:shrub species richness; DG:degradation degree; AB:total aboveground biomass; EAB:effective aboveground biomass; GAB:gramineous aboveground biomass; AAB:annual and biennial aboveground biomass; FAB:forb aboveground biomass; SAB:shrub aboveground biomass; LM:litter mass; PLS-DA:partial least squares discriminant analysis; RDA:redundancy analysis; H:Shannon-Wiener diversity; E:Pielou evenness; ANOVA:Two-way analysis of variance; SRA:Sequence Read Archive

\section{Declarations}

\section{Ethics approval and consent to participate}

Permits were obtained for Institute of Grassland Research, Chinese Academy of Agricultural Sciences of China and the National Commission on Research, China (31601994).

\section{Consent for publication}

Not applicable.

\section{Availability of data and materials}

Not applicable.

\section{Competing interests}

The authors declare there is no conflict of interest with this work.

\section{Funding}

This study was supported by Youth Fund of Shandong Provincial Natural Science Foundation, China [grant number ZR2016CQ11], and Youth Fund of National Natural Science Foundation of China [grant number 31601994].

\section{Authors' contributions}

XFB and YLS designed the research. HWD, PZ, YML, and LJ carried out sampling and data collection and compilation, and performed the statistical analyses. YLS and SWH wrote the manuscript, and funded this study. All authors read and approved the manuscript.

\section{Acknowledgements}

We thank Jian-Jun Chen, Xilinhot, Inner Mongolia, China for his kind help when authors went Xilinhot grasslands for investigating and sampling.

\section{References}

1. Balser TC, Firestone MK. Linking microbial community composition and soil processes in a California annual grassland and mixed-conifer forest. Biogeochemistry. 2005;73:395-415. 
2. Johnson D, Booth RE, Whiteley AS, Bailey MJ, Read DJ, Grime JP, Leake JR. Plant community composition affects the biomass, activity and diversity of microorganisms in limestone grassland soil. Eur J Soil Sci. 2003;54(4):671-7.

3. Guo YJ, Du QF, Li GD, Ni Y, Zhang Z, Ren WB, Hou XY. Soil phosphorus fractions and arbuscular mycorrhizal fungi diversity following long-term grazing exclusion on semi-arid steppes in Inner Mongolia. Geoderma. 2016;269:79-90.

4. Faucon MP, Houben D, Lambers H. Plant functional traits: soil and ecosystem services. Trends Plant Sci. 2017;22(5):385-94.

5. Zak DR, Holmes WE, White DC, Peacock AD, Tilman D. Plant diversity, soil microbial communities, and ecosystem function: are there any links? Ecology. 2003;84(8):2042-50.

6. Ogram A, Bridgham S, Corstanje R, Drake H, Küsel K, Mills A, Newman S, Portier K, Wetzel R. Linkages between microbial community composition and biogeochemical processes across scales. In: Verhoeven JTA, Beltman B, Bobbink R, Whigham DF, editors. Wetlands and Natural Resource Management. Ecological Studies (Analysis and Synthesis). Vol. 190. Berlin: Springer; 2006. pp. 239-68.

7. Ebrahimi M, Khosravi H, Rigi M. Short-term grazing exclusion from heavy livestock rangelands affects vegetation cover and soil properties in natural ecosystems of southeastern Iran. Ecol Eng. 2016;95:10-8.

8. Chai QL, Ma ZY, Chang XF, Wu GL, Zheng JY, Li ZW, Wang GJ. Optimizing management to conserve plant diversity and soil carbon stock of semi-arid grasslands on the Loess Plateau. Catena. 2019;172:781-8.

9. Statistics Bureau of Xilingguole League. Statistical Yearbook of Xilinguole League. Beijing: China Statistics Press; 2008.

10. Li XL, Liu ZY, Wang Z, Wu XH, Li XL, Hu J, Shi HX, Guo FH, Zhang Y, Hou XY. Pathways of Leymus chinensis individual aboveground biomass decline in natural semiarid grassland induced by overgrazing: A study at the plant functional trait scale. PLoS ONE. 2015;10(5):e0124443.

11. Miao RH, Jiang DM, Musa A, Zhou QL, Guo MX, Wang YC. Effectiveness of shrub planting and grazing exclusion on degraded sandy grassland restoration in Horqin sandy land in Inner Mongolia. Ecol Eng. 2015;74:164-73.

12. Liu JH, Wu JJ, Su HB, Gao ZH, Wu ZT. Effects of grazing exclusion in Xilin Gol grassland differ between regions. Ecol Eng. 2017;99:271-81.

13. Golodets C, Kigel J, Sternberg M. Recovery of plant species composition and ecosystem function after cessation of grazing in a Mediterranean grassland. Plant Soil. 2010;329(1-2):365-78.

14. Deng L, Shangguan ZP, Wu GL, Chang XF. Effects of grazing exclusion on carbon sequestration in China's grassland. Earth-Sci Rev. 2017;173:84-95.

15. Cheng JM, Jing GH, Wei L, Jing ZB. Long-term grazing exclusion effects on vegetation characteristics, soil properties and bacterial communities in the semi-arid grasslands of China. Ecol Eng. 2016;97:170-8.

16. Zhang C, Li J, Wang J, Liu GB, Wang GL, Guo L, Peng SZ. Decreased temporary turnover of bacterial communities along soil depth gradient during a 35year grazing exclusion period in a semiarid grassland. Geoderma. 2019;351:49-58.

17. Chen XJ, Lin QM, Zhao XR, Chen H, Wen J, Li Y, Li GT. Long-term grazing exclusion influences arbuscular mycorrhizal fungi and their association with vegetation in typical steppe of Inner Mongolia, China. J Integr Agr. 2018;17(6):1445-53.

18. Li B. The rangeland degradation in north China and its preventive strategy. Sci Agr Sin. 1997;30(6):1-9.

19. Silva-Navas J, Moreno-Risueno MA, Manzano C, Téllez-Robledo B, Navarro-Neila S, Carrasco V, Pollmann S, Gallego FJ, del Pozo JC. Flavonols mediate root phototropism and growth through regulation of proliferation-to-differentiation transition. Plant Cell. 2016;28(6):1372-87.

20. Henry-Kirk RA, Plunkett B, Hall M, McGhie T, Allan AC, Wargent JJ, Espley RV. Solar UV light regulates flavonoid metabolism in apple (Malus $\times$ domestica). Plant Cell Environ. 2018;41(3):675-88.

21. Huang J, Pang CY, Fan SL, Song MZ, Yu JW, Wei HL, Ma QF, Li LB, Zhang C, Yu SX. Genome-wide analysis of the family 1 glycosyltransferases in cotton. Mol Genet Genomics. 2015;290(5):1805-18.

22. Hu ZM, Li SG, Guo Q, Niu SL, He NP, Li LH, Yu GR. A synthesis of the effect of grazing exclusion on carbon dynamics in grasslands in China. Global Change Biol. 2016;22(4):1385-93.

23. Wang D, Wu GL, Zhu YJ, Shi ZH. Grazing exclusion effects on above-and below-ground C and N pools of typical grassland on the Loess Plateau (China). Catena. 2014;123:113-20.

24. Loranger-Merciris G, Barthes L, Gastine A, Leadley P. Rapid effects of plant species diversity and identity on soil microbial communities in experimental grassland ecosystems. Soil Biol Biochem. 2006;38(8):2336-43.

25. Liu ZF, Fu BJ, Zheng XX, Liu GH. Plant biomass, soil water content and soil N:P ratio regulating soil microbial functional diversity in a temperate steppe: A regional scale study. Soil Biol Biochem. 2010;42(3):445-50.

26. Lozano YM, Hortal S, Armas C, Pugnaire Fl. Interactions among soil, plants, and microorganisms drive secondary succession in a dry environment. Soil Biol Biochem. 2014;78:298-306.

27. Spehn EN, Joshi J, Schmid B, Alphei J, Körner C. Plant diversity effects on soil heterotrophic activity in experimental grassland ecosystems. Plant Soil. 2000;224:217-30.

28. Fierer N, Jackson RB. The diversity and biogeography of soil bacterial communities. P Natl Acad Sci USA. 2006;103(3):626-31.

29. Cookson WR, Abaye DA, Marschner P, Murphy DV, Stockdale EA, Goulding KWT. The contribution of soil organic matter fractions to carbon and nitrogen mineralization and microbial community size and structure. Soil Biol Biochem. 2005;37(9):1726-37.

30. Huang ZQ, Xu ZH, Chen CR. Effect of mulching on labile soil organic matter pools, microbial community functional diversity and nitrogen transformations in two hardwood plantations of subtropical Australia. Appl Soil Ecol. 2008;40(2):229-39.

31. Hooper DU, Bignell DE, Brown VK, Brussaard L, Dangerfield JM, Wall DH, Wardle DA, Coleman DC, Giller KE, Lavelle P, Van Der Putten WH, De Ruiter PC, Rusek J, Silver WL, Tiedje JM, Wolters V. Interactions between aboveground and belowground biodiversity in terrestrial ecosystems: patterns,

Page $7 / 12$ 
mechanisms, and feedbacks: we assess the evidence for correlation between aboveground and belowground diversity and conclude that a variety of mechanisms could lead to positive, negative, or no relationship - depending on the strength and type of interactions among species. Bioscience. 2000;50(12):1049-61.

32. Tian J, McCormack L, Wang JY, Guo DL, Wang QF, Zhang XY, Yu GR, Blagodatskaya E, Kuzyakov Y. Linkages between the soil organic matter fractions and the microbial metabolic functional diversity within a broad-leaved Korean pine forest. Eur J Soil Biol. 2015;66:57-64.

33. Zhu XY, Shen CY, Chen GW, Zhang W, Li BG, Wang G. Advancement in research on bacterial chemotaxis in soil. Acta Pedol Sin. 2019;56(2):259-75.

34. de Weert S, Vermeiren H, Mulders IH, Kuiper I, Hendrickx N, Bloemberg GV, Vanderleyden J, De Mot R, Lugtenberg BJ. Flagella-driven chemotaxis towards exudate components is an important trait for tomato root colonization by Pseudomonas fluorescens. Mol Plant Microbe In. 2002;15(11):1173-80.

35. Chen ZZ. The landform and climate in Xilin river basin. Res Grassland Ecosyst. 1988;3:19-20.

36. Baoyin T, Liu ML, Li XL. The study on dynamics succession of community in degenerated steppe of Leymus chinensis after shallow ploughing. Acta Phytoecol Sin. 2003;27(2):270-7.

37. research survey of Inner Mongolia Grassland Ecosystem Research Station of the Chinese Academy of Sciences

Jiang S. Establishment. and research survey of Inner Mongolia Grassland Ecosystem Research Station of the Chinese Academy of Sciences. Grassland

Ecosystem Issue 1. Beijing: Science Press; 1985. p. 1-10.

38. Jackson ML. Soil chemical analysis. Englewood Cliffs: Prentice-Hall Inc.; 1958.

39. Jones JB. Soil testing in the United States. Commun Soil Sci Plan. 1973;4:307-22.

40. Li YK. Routine analytical method of soil agrochemistry. Beijing: Science Press; 1983. pp. 67-77.

41. West NE. Biodiversity of rangelands. J Range Manage. 1993;46(1):2-13.

\section{Tables}

Table 1 Correlations between vegetation parameters and grassland degradation gradient

\begin{tabular}{|llllllllll}
\hline & SR & AB & H & E & ESR & EAB & LM & BB \\
\hline GE & $15.67 \pm 2.22 \mathrm{a}$ & $268.79 \pm 66.22 \mathrm{a}$ & $2.07 \pm 0.14 \mathrm{a}$ & $0.76 \pm 0.08 \mathrm{a}$ & $12.00 \pm 2.00 \mathrm{a}$ & $246.00 \pm 75.96 \mathrm{a}$ & $91.37 \pm 37.56 \mathrm{a}$ & $268.79 \pm 66.22 \mathrm{a}$ & $5.67 \pm 0.89 \mathrm{a}$ \\
\hline FG1 & $8.33 \pm 0.44 \mathrm{~b}$ & $159.93 \pm 8.17 \mathrm{~b}$ & $1.15 \pm 0.20 \mathrm{~b}$ & $0.54 \pm 0.11 \mathrm{a}$ & $6.67 \pm 0.44 \mathrm{~b}$ & $157.41 \pm 10.97 \mathrm{~b}$ & $17.96 \pm 3.17 \mathrm{~b}$ & $159.93 \pm 8.17 \mathrm{a}$ & $4.67 \pm 0.44 \mathrm{a}$ \\
\hline FG2 & $10.00 \pm 0.67 \mathrm{~b}$ & $161.66 \pm 14.38 \mathrm{~b}$ & $1.50 \pm 0.08 \mathrm{~b}$ & $0.66 \pm 0.05 \mathrm{a}$ & $8.33 \pm 0.44 \mathrm{a}$ & $160.40 \pm 14.93 \mathrm{~b}$ & $5.41 \pm 0.36 \mathrm{~b}$ & $161.66 \pm 14.38 \mathrm{a}$ & $4.33 \pm 0.44 \mathrm{a}$ \\
\hline FG3 & $8.33 \pm 1.11 \mathrm{~b}$ & $137.22 \pm 35.10 \mathrm{~b}$ & $1.06 \pm 0.16 \mathrm{~b}$ & $0.51 \pm 0.08 \mathrm{a}$ & $6.00 \pm 0.67 \mathrm{~b}$ & $27.97 \pm 5.62 \mathrm{c}$ & $0.00 \pm 0.00 \mathrm{~b}$ & $137.22 \pm 35.10 \mathrm{a}$ & $4.00 \pm 0.00 \mathrm{a}$ \\
\hline r & -0.656 & -0.614 & -0.742 & -0.626 & -0.706 & -0.869 & -0.729 & -0.026 & -0.63 \\
\hline $\begin{array}{l}P \\
\text { value }\end{array}$ & $\mathbf{0 . 0 2 1}$ & $\mathbf{0 . 0 3 4}$ & $\mathbf{0 . 0 0 6}$ & $\mathbf{0 . 0 2 9}$ & $\mathbf{0 . 0 1 0}$ & $\mathbf{0 . 0 0 0}$ & $\mathbf{0 . 0 0 7}$ & 0.937 & \\
\hline
\end{tabular}

GE: grazing exclusion area; FG: free grazing area; SR: total plant species richness; $A B$ : total plant aboveground biomass ( $\mathrm{g} \mathrm{m}^{-2}$ ); $\mathrm{H}_{\mathrm{S}} \mathrm{Shannon-Wiener}$ diversity index; E: Pielou evenness index; ESR: effective species richness; EAB: effective species aboveground biomass ( $\left.\mathrm{g} \mathrm{m}^{-2}\right)$; $\mathrm{LM}$ : litter mass ( $\left.\mathrm{g} \mathrm{m}^{-2}\right)$; BB: total belowground biomass ( $\left.\mathrm{g} \mathrm{m}^{-3}\right)$; GSR: gramineous species richness; GAB: gramineous species aboveground biomass ( $\left.\mathrm{g} \mathrm{m}^{-2}\right)$; ASR: annual and biennial species richness; AAB: annual and biennial species aboveground biomass $\left(\mathrm{g} \mathrm{m}^{-2}\right)$; FSR: forb species richness; FAB: forb species aboveground biomass ( $\left.\mathrm{g} \mathrm{m}^{-2}\right)$; $\mathrm{SSR}$ : shrub species richness; SAB: shrub species aboveground biomass $\left(\mathrm{g} \mathrm{m}^{-2}\right)$. $r$ indicated the corresponding Pearson correlations

Table 2 Correlations between soil properties, enzyme activities and grassland degradation gradient

\begin{tabular}{|llllllllll}
\hline & SBD & SWC & PH & TN & AHN & TP & AP & TK & AK \\
\hline GE & $1080.15 \pm 81.74 a$ & $4.81 \pm 0.48 \mathrm{a}$ & $7.18 \pm 0.04 \mathrm{a}$ & $0.90 \pm 0.12 \mathrm{a}$ & $92.42 \pm 5.74 \mathrm{a}$ & $0.29 \pm 0.02 \mathrm{a}$ & $6.53 \pm 0.36 \mathrm{a}$ & $35.14 \pm 1.87 \mathrm{a}$ & $17.39 \pm 3.94 \mathrm{ab}$ \\
\hline FG1 & $1437.21 \pm 14.72 \mathrm{a}$ & $3.64 \pm 0.26 \mathrm{a}$ & $7.86 \pm 0.15 \mathrm{a}$ & $0.51 \pm 0.11 \mathrm{ab}$ & $33.13 \pm 5.21 \mathrm{~b}$ & $0.19 \pm 0.02 \mathrm{ab}$ & $3.57 \pm 0.27 \mathrm{~b}$ & $36.93 \pm 0.001 \mathrm{a}$ & $12.78 \pm 3.70 \mathrm{ab}$ \\
\hline FG2 & $1463.47 \pm 53.99 \mathrm{a}$ & $3.28 \pm 0.10 \mathrm{a}$ & $7.31 \pm 0.04 \mathrm{a}$ & $0.48 \pm 0.02 \mathrm{~b}$ & $43.05 \pm 2.72 \mathrm{~b}$ & $0.14 \pm 0.02 \mathrm{~b}$ & $0.27 \pm 0.02 \mathrm{c}$ & $36.93 \pm 0.001 \mathrm{a}$ & $11.23 \pm 0.27 \mathrm{~b}$ \\
\hline FG3 & $1407.05 \pm 49.55 \mathrm{a}$ & $3.53 \pm 0.44 \mathrm{a}$ & $7.21 \pm 0.10 \mathrm{a}$ & $0.62 \pm 0.03 \mathrm{ab}$ & $52.50 \pm 3.66 \mathrm{~b}$ & $0.17 \pm 0.01 \mathrm{ab}$ & $5.24 \pm 1.04 \mathrm{ab}$ & $36.93 \pm 0.001 \mathrm{a}$ & $22.66 \pm 1.54 \mathrm{a}$ \\
\hline $\mathbf{r}$ & 0.528 & -0.513 & -0.120 & -0.358 & -0.425 & -0.559 & 0.005 & 0.408 & 0.499 \\
\hline $\begin{array}{l}P \\
\text { value }\end{array}$ & 0.078 & 0.088 & 0.711 & 0.254 & 0.168 & 0.059 & 0.987 & 0.118 & \\
\hline
\end{tabular}

GE: grazing exclusion area; FG1: free grazing area 1; FG2: free grazing area 2; FG3: free grazing area 3; SBD: soil bulk density (g $\mathrm{m}^{-3}$ ); SWC: soil water content (\%, $\mathrm{g} \mathrm{g}^{-1}$ fresh weight); $\mathrm{PH}$ : soil $\mathrm{pH}$ value; TN: total nitrogen content $\left(\mathrm{g} \mathrm{kg}^{-1}\right)$; AHN: alkali-hydrolyzable nitrogen content (mg kg-1 $)$; TP: total phosphorus content $\left(\mathrm{g} \mathrm{kg}^{-1}\right)$; AP: available phosphorus content $\left(\mathrm{mg} \mathrm{kg}^{-1}\right)$; TK: total potassium content $\left(\mathrm{g} \mathrm{kg}^{-1}\right)$; AK: available potassium content (mg kg $\left.{ }^{-1}\right)$; SOM: soil organic matter $\left(\mathrm{mg} \mathrm{g}^{-1}\right)$. Phosphatase: phosphatase activity, [1U=1 mg P $\left.\mathrm{O}_{5} /(100 \mathrm{~g} \cdot 2 \mathrm{~h})\right]$; Sucrase: Sucrase activity, [1U=1 mg glucose / (g.24 h)]; Urease: urease activity, $\left.\left[1 \mathrm{U}=1 \mu \mathrm{g} \mathrm{NH} \mathrm{N}_{3} \mathrm{~N} / \mathrm{g} \cdot 24 \mathrm{~h}\right)\right]$. r indicated the corresponding Pearson correlations 
Table 3 The correlations between bacterial community and different environmental factors related with vegetation biomass, diversity, and soil properties based on Mantel test

\begin{tabular}{|lllll|}
\hline Matrix A & Matrix B & $r$ & $P$ value & Permutations \\
\hline Bacterial relative abundance & Vegetation biomass factors & 0.281 & 0.035 & 9999 \\
\hline Bacterial relative abundance & Vegetation diversity factors & 0.342 & 0.025 & 9999 \\
\hline Bacterial relative abundance & Soil properties & 0.731 & NT & 9999 \\
\hline Bacterial absolute abundance & Vegetation biomass factors & 0.256 & 0.047 & 9999 \\
\hline Bacterial absolute abundance & Vegetation diversity factor & 0.340 & 0.021 & 9999 \\
\hline Bacterial absolute abundance & Soil properties & 0.641 & NT & 9999 \\
\hline
\end{tabular}

Matrix A indicated corresponding OUT matrix; Matrix B indicated corresponding environmental factor matrix; r indicated the corresponding Pearson correlations; Permutations indicated the times of permutation; NT indicated the value was less than 0.001

\section{Figures}

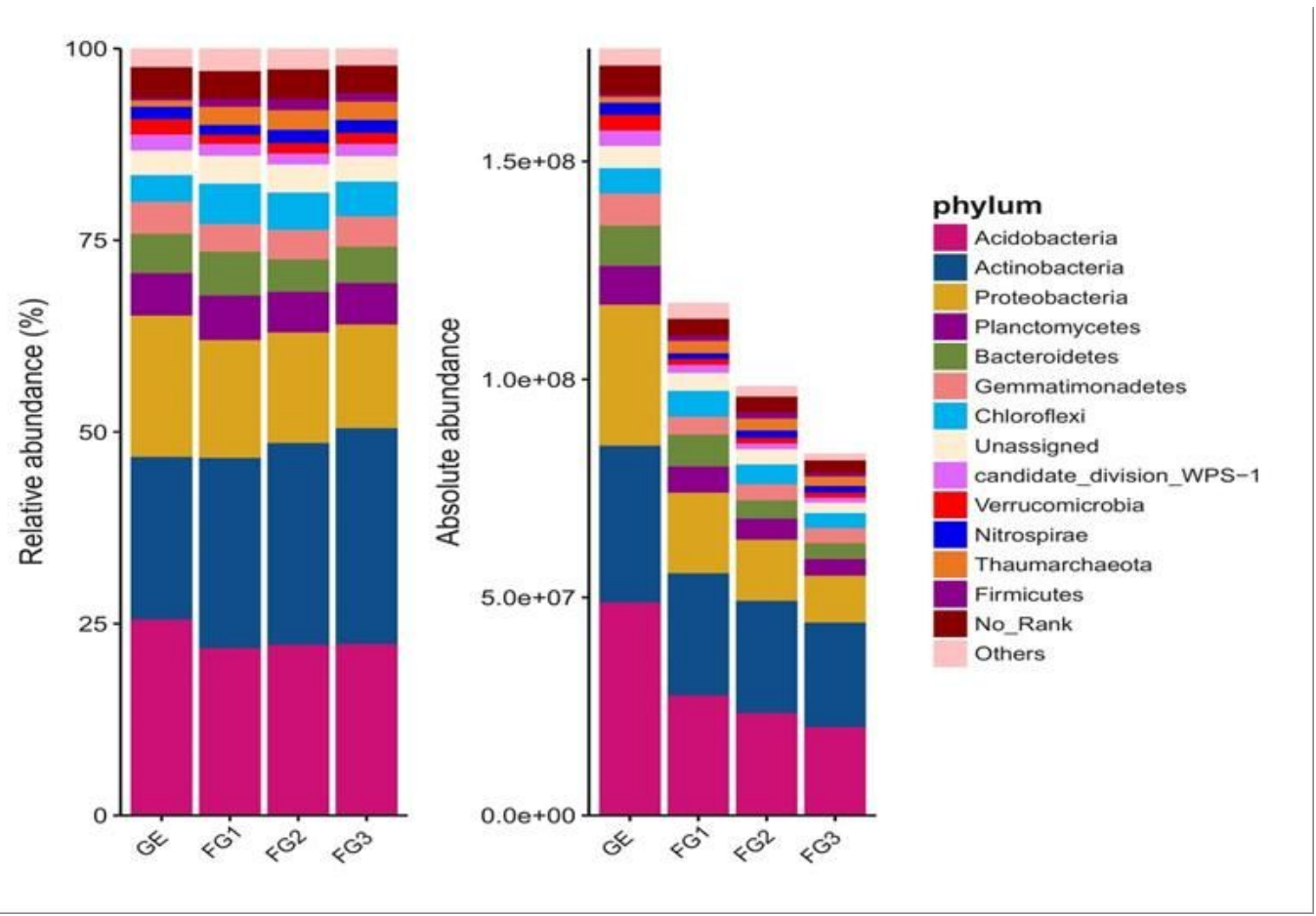

\section{Figure 1}

Absolute abundance, relative abundance and major bacterial community composition barplot at the phylum level across for different soil layers in free grazing and long-term grazing exclusion grasslands
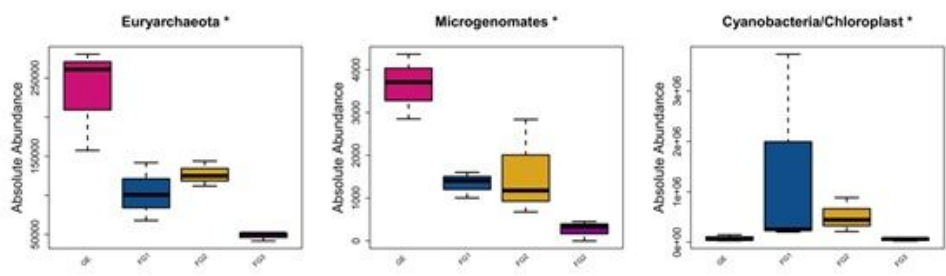

Figure 2

Differential absolute abundant features analysis of phylum level among four study sites based on Kruskal-Wallis test at a significant level of $\mathrm{P}<0.05$ 

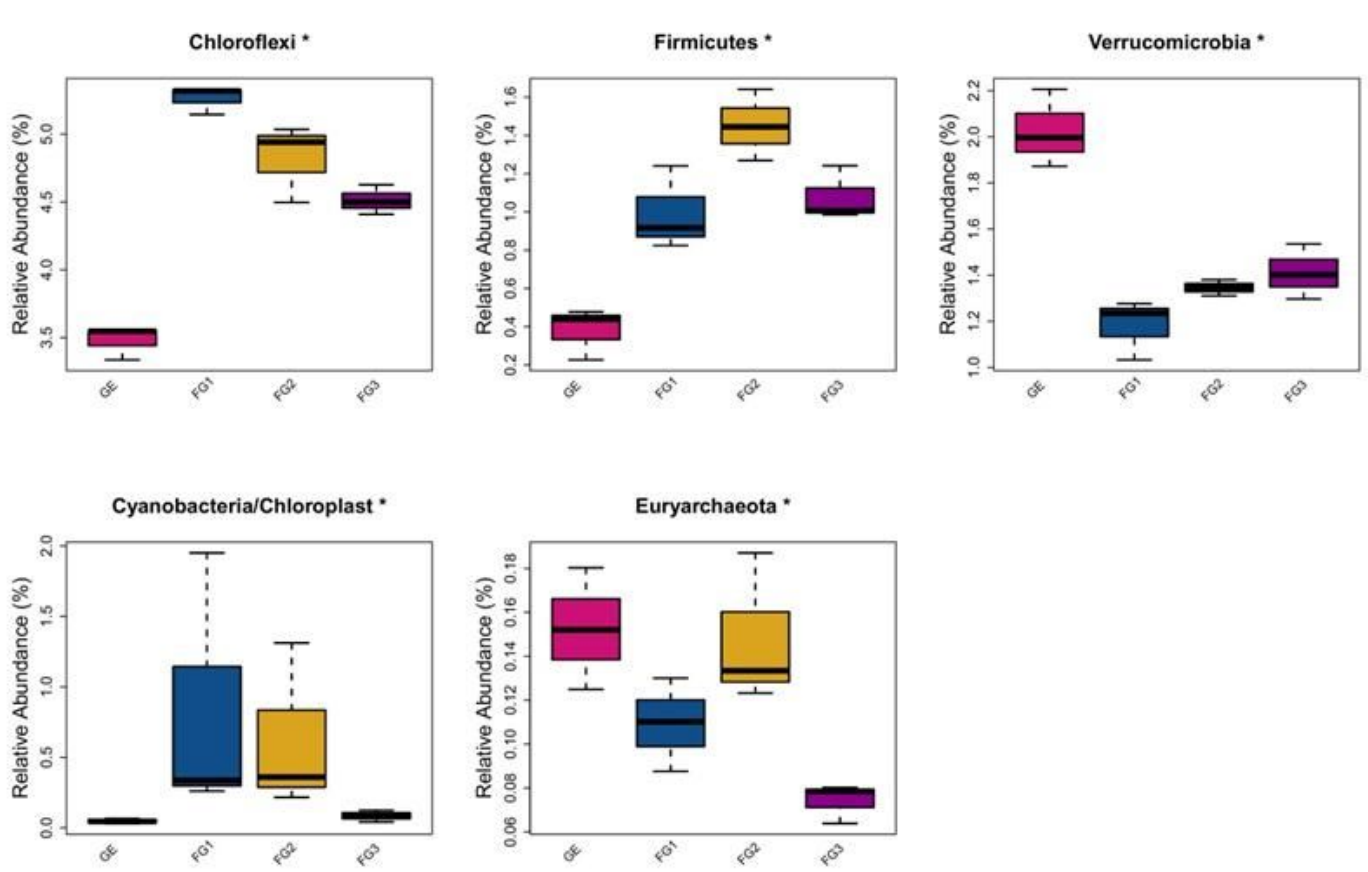

\section{Figure 3}

Differential relative abundant features analysis of phylum level among four study sites based on Kruskal-Wallis test at a significant level of $\mathrm{P}<0.05$

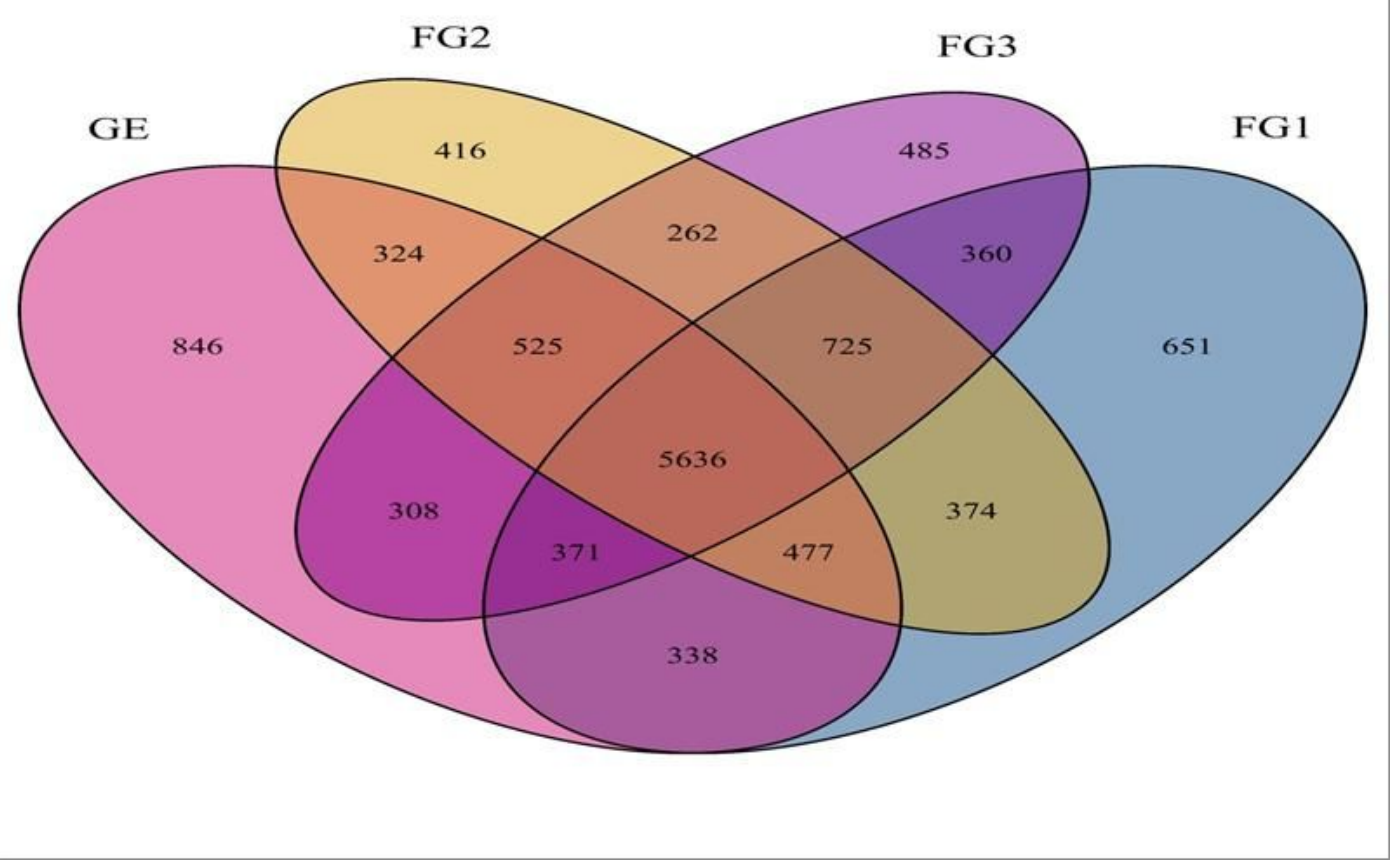

\section{Figure 4}

Venn map constructed by soil samples from four study sites 


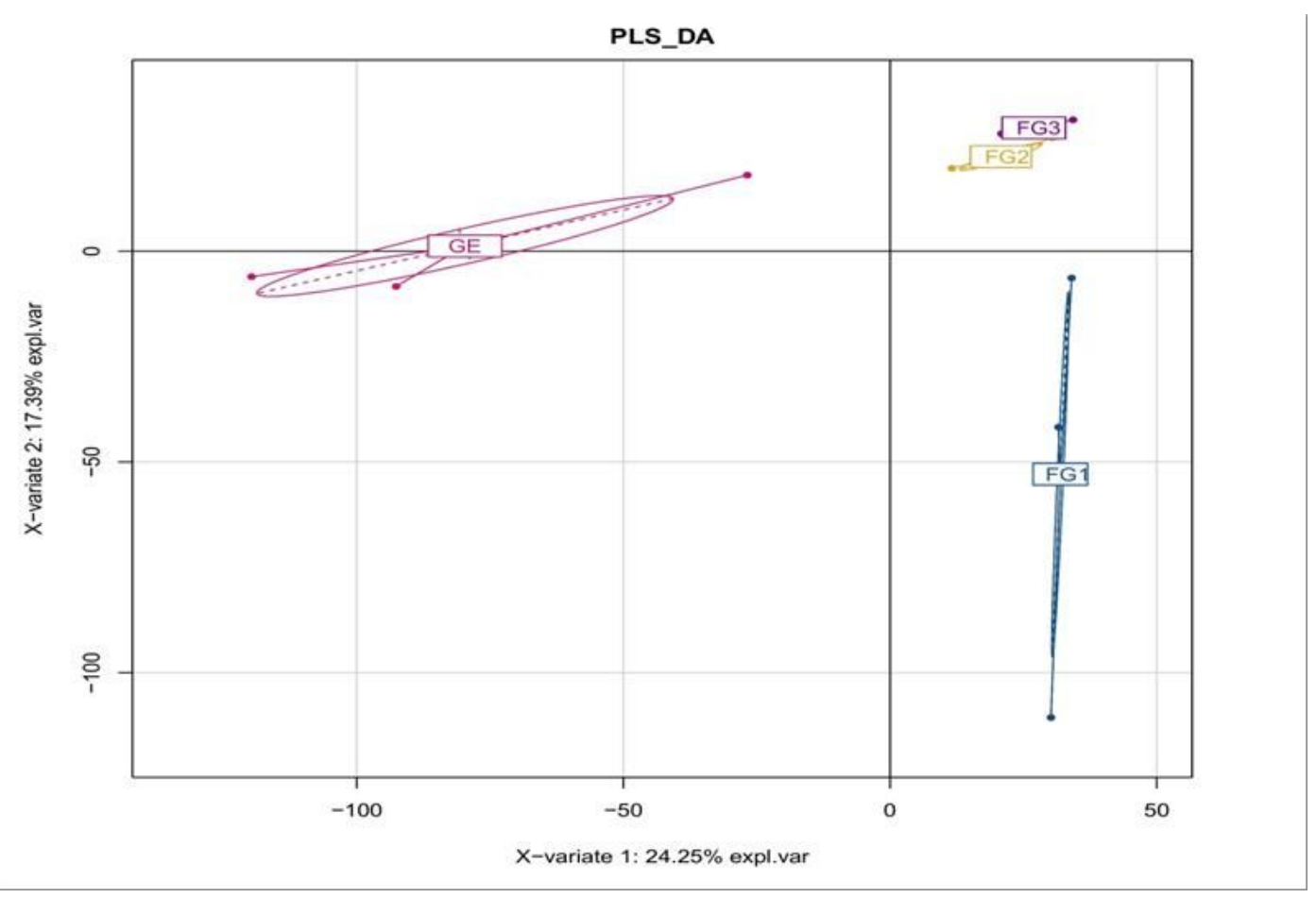

Figure 5

Partial least squares discriminant analysis (PLS-DA) across for grazing exclusion and free grazing areas
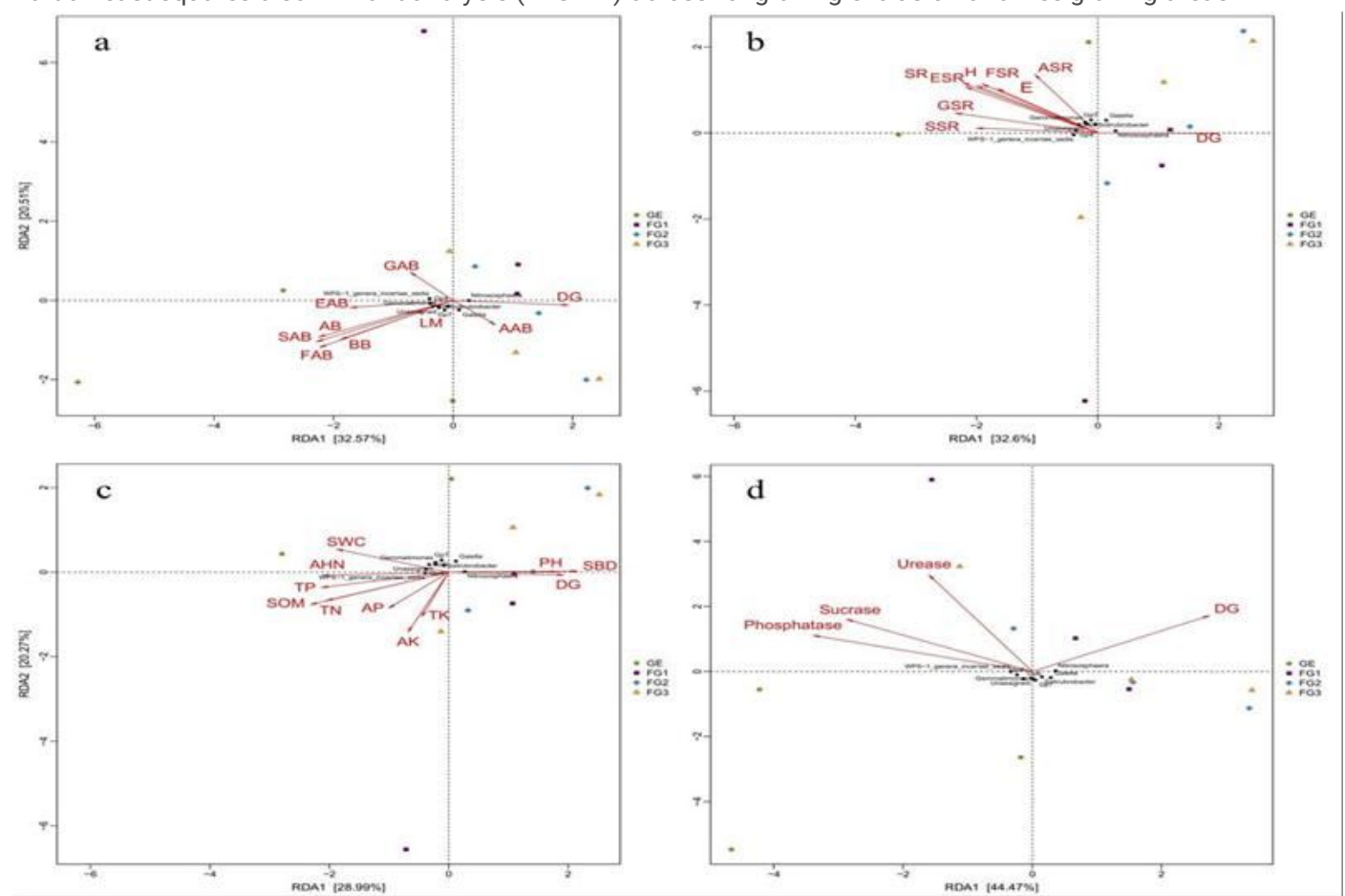

Figure 6

Redundancy analysis (RDA) result of soil bacterial community with vegetation biomass factors (a), vegetation diversity factors (b), soil physical and chemical properties (c), and soil enzyme activities (d). DG: degradation degree; AAB: annual and biennial species aboveground biomass; LM: litter mass; BB: total belowground biomass; FAB: forb species aboveground biomass; $S A B$ : shrub species aboveground biomass; $A B$ : total aboveground biomass; EAB: effective species aboveground biomass; GAB: gramineous species aboveground biomass; SSR: shrub species richness; GSR: gramineous species richness; ESR: effective species richness; H: Shannon-Wiener diversity index; E: Pielou evenness index; SR: total species richness; FSR: forb species richness; ASR: annual and biennial species richness; $\mathrm{PH}$ : soil pH value; SBD: soil bulk density; TK: total potassium content; AK: available potassium content; AP: available phosphorus content; TN: total nitrogen content; SOM: soil organic matter content; TP: total phosphorus content; AHN: alkali-hydrolyzable nitrogen content; SWC: soil water content 


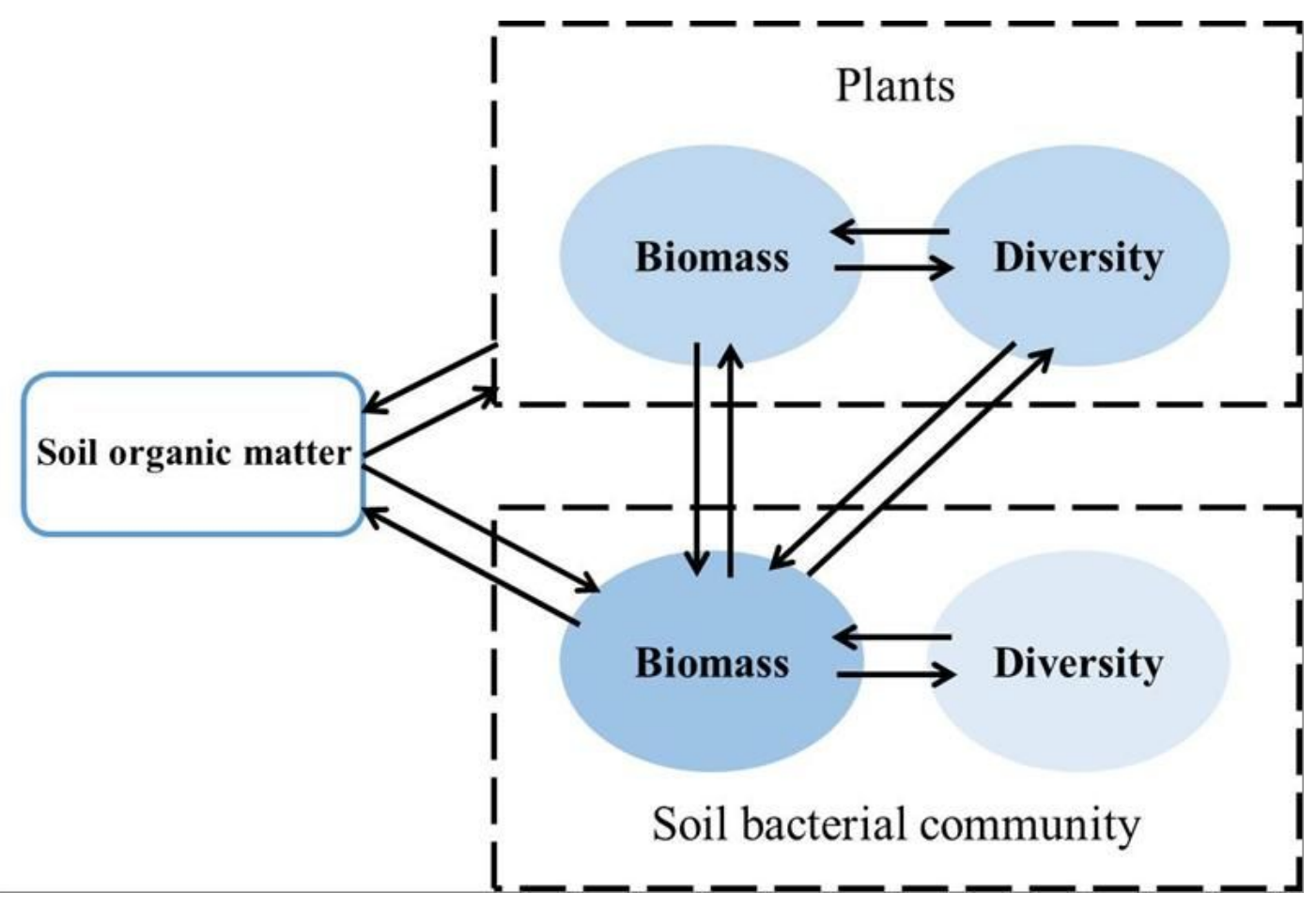

Figure 7

The interaction schema between plant and soil 